implementation, in accordance with the Colombian requirements and regulations in this matter, having a recent policy and advancing in the design of processes, procedures and manuals; There are no tangible results of the evaluation of the system and specific improvement actions.

Discussion There is a need to refine the planning and implementation of strategies that contribute to the proper implementation of the SGSST; To train a greater number of the brigade, minimising the impact by the rotation of the staff. Disseminate in greater degree the politics, strategies and activities in the university community. It is necessary to design workshops according to their functions that allow them to make use of the protection elements available to them, since their perception shows that the main cause of accidents is caused by human errors.

\section{SAFE EMPLOYMENT INTEGRATION OF NEWCOMERS TO CANADA}

${ }^{1}$ Agnieszka Kosny*, ${ }^{1}$ Basak Yanar, ${ }^{2}$ Momtaz Begum, ${ }^{3}$ Stephanie Premji, ${ }^{1}$ Dina Al-Khooly. ${ }^{1}$ Institute for Work and Health, Toronto, Ontario, Canada; ${ }^{2}$ Access Alliance Multicultural Health and Community Senvices Centre, Toronto, Ontario, Canada; ${ }^{3}$ McMaster University, Hamilton, Ontario, Canada

\subsection{6/oemed-2018-ICOHabstracts.89}

Introduction Settlement and integration involves helping recent immigrants and refugees find work and become economically solvent. Yet many newcomers end up in 'survival jobs' that are precarious, physically demanding and expose workers to hazards. While 'welcome materials' and settlement programs help newcomers find employment, few offer guidance on employment rights, employer responsibilities and how to stay safe at work. We know very little about how newcomers prepare for employment, the types of resources needed or which groups are well-positioned to deliver these resources.

Methods Semi-structured interviews were conducted with policy makers, program developers, social service providers involved in immigrant settlement and employment preparation $(n=20)$. Eighteen focus groups were also conducted with newcomers looking for work and those who had found their first jobs in Canada. The study examined the employment preparation and job search process; newcomer experiences in their first jobs; key training and resource needs related to safe work integration. Data were coded by two researchers and a thematic, inductive analysis was carried out. The constant comparative method was used to understand how newcomers come to understand their rights and where there are gaps in resources and training.

Findings Our findings suggest that while many programs focus on employment preparation, the delivery of OHS and rightsrelated resources is haphazardly and hampered by a lack of consistent funding, time constraints and a diffusion of responsibility. Newcomers reported difficulty finding work and taking jobs that were incommensurate with their experience and education. Many took on informal work without training or compensation as a means of gaining Canadian experience. Participants had poor understanding of rights and responsibilities in the workplace and many had not received comprehensive OHS training. The use of community networks, while useful in finding employment, could be a barrier to speaking up in the workplace. Language barriers were an obstacle to finding work and invoking workplace rights.

Discussion This study adds to our understanding of what can help recent immigrants and refugees successfully prepare for and stay in good quality, safe jobs. We identify optimal points in the settlement process where employment-related resources can be provided and the role social service agencies, regulatory bodies and employers should play.

\section{DO SELF-REPORTS OF MUSCULOSKELETAL SYMPTOMS PREDICT OCCUPATIONAL ACCIDENTS? EVIDENCES FROM A HOSPITAL-BASED CASE-CONTROL STUDY IN BRAZIL}

João Marcos Bernardes*, Maila Karina Mattos Brito, Adriano Dias. Botucatu Medical School/UNESP, Botucatu, Brazil

\subsection{6/oemed-2018-ICOHabstracts.90}

Introduction It was estimated that there were over 313 million non-fatal occupational accidents worldwide in 2010. In order to reduce occupational accident rate, it is necessary to determine its associated factors. Musculoskeletal symptoms have been shown: to act as a mediating factor between ergonomic conditions and occupational accidents; to be associated with perceived risk of injury; and to increase the probability of accidents. Therefore, the aim of this study was to investigate whether self-reports of musculoskeletal symptoms were associated with occupational accidents occurrence.

Methods A hospital-based case control study was conducted among workers aged 17-59 years and residing in Botucatu, Brazil. The study included cases of occupational accidents that required hospitalisation. Controls were patients who suffered a non-work-related accident. Altogether, 80 cases and 125 controls were included. Self-reports of musculoskeletal symptoms were obtained using the Nordic Musculoskeletal Questionnaire, while a standardised questionnaire was used to assess socio-demographic factors. Frequency statistics and logistic regression were conducted to analyse the data.

Result The highest musculoskeletal symptoms prevalence was for the low back, followed by shoulders and the upper back. Self-reports of upper back musculoskeletal symptoms in the last 7 days and the occurrence of occupational accidents were associated (OR=3.670, 95\% CI: 1.503 to 8.963 ).

Discussion According to our results, musculoskeletal symptoms in the upper back do predict occupational accidents. However, we believe that further studies, with a method of musculoskeletal symptoms assessment capable of discriminating between serious and minor complaints, are necessary to determine whether self-reports of musculoskeletal symptoms in other regions are also associated with the occurrence of occupational accidents.

\section{PUSHING AND PULLING ASSESSMENT: HOW TO DEAL WITH INTER-OPERATOR VARIABILITY}

${ }^{1} \mathrm{G}$ De Vito*, 'MA Riva, ${ }^{2} \mathrm{M}$ Marinelli, ${ }^{3} \mathrm{~A}$ Vitale, ${ }^{3} \mathrm{M}$ Sormani, ${ }^{3} \mathrm{M}$ Belingheri, ${ }^{3} \mathrm{M}$ Turato, ${ }^{2} \mathrm{R}$ Latocca. 'School of Medicine and Surgery, University of Milan Bicocca, Milan, Italy; ${ }^{2}$ Occupational Health Unit, Manzoni Hospital, Lecco, Italy; ${ }^{3}$ School of Specialisation in Occupational Health, University of Milan, Milan, Italy; ${ }^{4}$ Occupational Health Unit, San Gerardo Hospital, Monza, Italy

\subsection{6/oemed-2018-ICOHabstracts.91}

Introduction Snook and Ciriello has been the leading methods to assess pushing and pulling for roughly 30 years. ISO112282 integrated it providing useful add-ons. On duties, workers apply excessive amount of force, for reasons either related to organisational, technical or legal issues. Therefore, inter-operator variability still remains a main issue to be addressed. 
Methods 378 pushing and pulling test sessions were organised. Forces were measured by means of a computerised dynamometer $(200 \mathrm{~Hz}, 120 \mathrm{Kg}$ scale). 3 health operators $(\mathrm{OH})$ and 2 very trained technicians (T) moved 2 types of hospital beds carrying simulated loads of patients weighting 70, 90 and $110 \mathrm{Kg}$, on a maximum distance of $300 \mathrm{~m}$. To assess the speed limit ( $1 \mathrm{~m} /$ second) compliance, a $20 \mathrm{~m}$ pushing test was repeated multiple times by each tester. The same $20 \mathrm{~m}$ test provided individual threshold to compute initial and sustained forces. Initial force was defined as value lying above the threshold, the hysteresis curve and only for coherent data. To compare the speed suggested by the methods with the real speed performed by operators, a 2 months analysis of the patient transportation recorded missions was carried out. Then the accumulated delay-times were estimated with reference to the mean travel time measured at the suggest speed.

Results Initial forces resulted 43\% (32\%-112\%) and sustained forces 37\% (23\%-101\%) higher and statistically significant for $\mathrm{OH}$ compared to T. Increased speed saves only $25 \%(12 \%-56 \%)$ of the travel time, due to elevators waiting, doors opening etc.

Conclusion Rapidly grooving hospitals often show tortuous paths, where patient transportation on bed is allowed. ISO11228-2 assessment method contribute to solve complex measures, particularly when dealing very long distance pushing and pulling tasks. Initial forces might be calculated by measuring the threshold of the initial force of each operator on a $20 \mathrm{~m}$ test. Mean delay time shows risk excess often leading to increased speed behaviours.

\section{Ageing and Work}

\section{STAYING AT WORK WHILE AGEING: BARRIERS AND FACILITATORS FOR WORKERS OVER 55 YEARS OF AGE}

M-J Durand*, M-F Coutu. Université de Sherbrooke, Longueuil, Canada

\subsection{6/oemed-2018-ICOHabstracts.92}

Introduction While ageing workers (AWs) ( $\geq 55$ years) constitute a growing portion of the labour force, they tend to be absent for health reasons more often than other workers. However, implementing mechanisms that facilitate their staying at work implies first understanding the contributing factors and dynamics.

Methods A multimethod approach was used, combining a literature review and a series of group discussions with stakeholders in work disability. First, a rapid review of mixed studies (qualitative, quantitative, mixed) was carried out between 2006 and 2016 using main databases (e.g.: CINAHL, PsycInfo, Sociological Index). We identified 30 articles on AWs and various causes of disability, then analysed the article content using a predefined extraction grid. Four focus groups representing various stakeholders $(n=35)$ concerned by the ageing of workers in Quebec, Canada, were formed (insurers, employers, unions, health professionals). The discussions were transcribed and content analysis was performed.

Results Combined results revealed that the relationship between ageing and the likelihood of staying at work is largely influenced by the interactions between workers' personal systems and the organisation's (workplace) system. The gap between workers' representations, capacities and resources, on the one hand, and employers' expectations and requirements and the conditions they provide, on the other, significantly impacts the likelihood of AWs staying at work.

Discussion The likelihood of AWs staying at work appears closely linked to the workplace's dynamic capacity to take into account their specific health conditions and needs. This presupposes, however, recognition of AWs' added value, in a market characterised by ever-growing concern with maximising performance. The actions associated with the different systems (e.g. compensation and healthcare systems) also need to be harmonised to maximise the stay-at-work potential of this segment of the labour force.

\section{AGEING AND INTERVENTIONS}

Clas-Håkan Nygård*. University of Tampere, Finland

\subsection{6/oemed-2018-ICOHabstracts.93}

Aim of special sessions To show and discuss results from interventions among ageing workers in different occupations.

${ }^{1}$ Subas Neupane, ${ }^{2}$ Magnavita N, ${ }^{3}$ Sirpa Lusa, ${ }^{4}$ Judith Sluiter, ${ }^{1}$ Clas-Håkan Nygård

${ }^{1}$ University of Tampere, Tampere, Finland

${ }^{2}$ Università Cattolica del Sacro Cuore, Italy

${ }^{3}$ Finnish Institute of Occupational Health

${ }^{4}$ Academic Medical Centre, Coronel Institute of Occupational Health, Amsterdam, The Netherlands

\section{0a HOW TO PROMOTE HEALTH AND WORK ABILITY OF FIREFIGHTERS USING COMPUTER-BASED ASSESSMENT METHOD OF PHYSICAL WORK CAPACITY}

${ }^{1} \mathrm{~S}$ Lusa*, ${ }^{2} \mathrm{~A}$ Punakallio, ${ }^{2} \mathrm{~J}$ Halonen, ${ }^{2} \mathrm{M}$ Wikström. ${ }^{1}$ Finnish Institute of Occupational Health, Tampere, Finland; ${ }^{2}$ Finnish Institute of Occupational Health, Helsinki, Finland

\subsection{6/oemed-2018-ICOHabstracts.94}

Introduction According to the Finnish regulations the health and physical work capacity of operative firefighters has to meet the demands of work throughout their career, therefore they must be evaluated regularly. This study is part of large research and developmental project of the assessment, feedback and follow-up method of firefighters' physical work capacity (FireFit method).

Methods The aim was to find out short term effectiveness of the use of FireFit method. Web-based questionnaire was sent to 18 actors of all 22 regional rescue services (RRS) and to their occupational health personnel (OHP). The response rate was $60 \%$. In addition, the actors of two RRS and their OHP were interviewed about the developmental needs of the method especially concerning ageing firefighters.

Result The quality, equality and the use of tests in professional manner has improved. They reported that it has been easier to influence the problems of work ability using the system. As a whole, the comprehensive and work related feedback from the assessments has made discussion easier leading to the real causes of the problems and to wider health promotion issues. The consultation of OHP has been more prevalent and early enough, especially for persons with musculoskeletal problems. A total of $77 \%$ of the respondents felt that the quality and comprehensiveness of physical training has improved. However, there were also developmental needs. For example, in all RRS there should be an established and well-known action 